\title{
The yield of routine histopathology in fistula-in-ano
}

\author{
Umesh Jayarajah, Isuru Sampath Almeida, Dharmabandhu Nandadeva Samarasekera \\ Department of Surgery, Faculty of Medicine, University of Colombo, Sri Lanka
}

Keywords: fistula-in-ano; histopathology; tuberculosis; Crohn's disease

\begin{abstract}
Introduction

Fistulae-in-ano with a specific aetiology such as TB and Crohn's are usually complex and challenging to treat. This study was aimed to determine the yield of routine histological analysis in fistula-in-ano, in detecting specific aetiology.
\end{abstract}

\section{Methods}

A descriptive study was conducted at the Professorial Surgical Unit, National Hospital of Sri Lanka, Colombo from 2001-2016. Histopathology reports of all patients without a histological diagnosis and who underwent surgery for fistulae-in-ano were analysed.

\section{Results}

A total of 215 patients [median age:40 years (range:14-73), males $=179(82.8 \%)]$ were analysed. The majority $(75 \%$, $\mathrm{n}=161$ ) were simple fistulae. Histological evaluation revealed inflamed granulation tissue in $94.9 \%(n=204)$ of patients. Five $(2.3 \%)$ patients had conclusive evidence of Crohn's disease and three (1.4\%) had tuberculosis. One patient $(0.5 \%)$ had evidence of adenocarcinoma with mucinous differentiation. Significant proportion of fistula with underlying specific aetiology were complex fistulae (82\% vs. $22 \%, \mathrm{p}<0.001)$ and associated with abscess/collections (45.5\% vs. $11.8 \%, \mathrm{p}<0.001)$. Age, type of fistula, level of internal opening, recurrence and presence of haemorrhoids were comparable in those with and without a specific aetiology.

\section{Conclusions}

Complex fistula and the presence of abscess/ collection were associated with a specific aetiology. Routine histopathological analysis in patients presenting with fistula in-ano should be performed as a clinical prediction based on the nature of fistula may not be always accurate.

Correspondence: D. N. Samarasekera

E-mail: samarasekera58@yahoo.co.uk

(iD https://orcid.org/0000-0003-2229-7549

Received: 13-05-2020 Accepted: 25-07-2020

DOI: http://doi.org/10.4038/sljs.v38i2.8698

The Sri Lanka Journal of Surgery 2020; 38(2): 37-41

\section{Introduction}

Fistula-in-ano is a benign anal condition which has been described in the literature for over 2500 years [1]. It is commonly encountered in colorectal surgical practice with a reported incidence of 8.6 per 100000 population [2]. The majority are simple fistulae which can be delineated fairly accurately and treated easily without significantly affecting the quality of life $[3,4]$. However, complex fistulae are challenging to treat and can have frequent recurrences requiring multiple surgeries [5].

Repeated surgical interventions can increase the risk of anal sphincter injury, which is often irreversible and can result in anal incontinence [6]. Some of these complex fistulae may have a specific cause which may be successfully managed medically such as tuberculosis (TB), Crohn's disease or actinomycosis. Diagnosis of these aetiological factors is aided by histopathological analyses. Studies that have analysed the histopathology of perianal fistula specimens to find a specific aetiology are few [7-10]. However, previous studies have not analysed the associated factors of specific aetiology in fistulain-ano.

Therefore, this study was aimed to determine the yield of routine histopathology in identifying a specific aetiology in patients undergoing surgical treatment for fistula-in-ano. Furthermore, the associated factors were also determined.

\section{Methods}

A retrospective analysis of the histopathology reports of the patients who underwent surgery for fistulae-in-ano without a diagnosis for the fistulae, over 6 years (from 2011-2016) at the Professorial Surgical Unit at the National Hospital of Sri Lanka was done. All examinations and investigations were carried out by a senior consultant colorectal surgeon. Data including demographic parameters, type of fistulae, number and type of procedures, the complexity of the fistula were prospectively entered into a computerised database.

Fistulae with multiple external openings, high transphincteric, suprasphincteric and extrasphincteric fistulae and/or with high blind extensions or horseshoe tracts and/or were anterior in a female patient were defined as complex fistulae $[11,12]$. The anatomy and complexity of the fistulae were 
assessed by endoanal ultrasonography and examination under anaesthesia. During examination under anaesthesia, a segment or the entire tract of the fistulae were sent for histological evaluation to look for a specific aetiology.

Data were analysed using SPSS version 20. Data were expressed using the odds ratio (OR), frequency and percentages where relevant. Pearson Chi-square test was used to determine associations. Statistical significance was determined at an alpha of 0.05. Ethical clearance was obtained from the Ethics Review Committee of the National Hospital of Sri Lanka.

\section{Results}

A total of 215 patients underwent surgical treatment for fistula-in-ano during the study period. Histopathological analyses were carried out for all fistulae. The median age of the participants was 40 years (range, 14- 73). Of the participants $82.8 \%(n=179)$ were males and $17.2 \%(n=36)$ were females. Around $75 \%(\mathrm{n}=161)$ were simple fistulae and $25 \%(n=54)$ were complex fistulae. Most were transphincteric fistulae $(60.5 \%, \mathrm{n}=130)$ followed by intersphincteric fistulae $(23.7 \%, \mathrm{n}=51)$. Other types were superficial $(n=28,13 \%)$, suprasphincteric $(n=5,2.3 \%)$ and extrasphincteric fistulae $(n=1,0.5 \%)$.

The majority of the histopathological analyses showed only the presence of inflamed granulation tissue and did not reveal any evidence of a specific aetiology $(n=204,94.9 \%)$.

Two $(0.9 \%)$ patients had inflamed granulation tissue containing non-caseating granulomata on histology. Further analysis with stains for acid-fast bacilli was negative and no conclusive evidence of Crohn's disease was seen. Five (2.3\%) patients had conclusive changes of Crohn's disease on histology. Three (1.4\%) had granulomatous changes and stains for acid-fast bacilli was conclusive of TB. One patient $(0.5 \%)$ had evidence of adenocarcinoma with mucinous differentiation.

The associated factors of a specific aetiology have been summarised in table 1. All patients with specific aetiology were males. A significantly higher proportion of those having a specific aetiology were complex fistulae (82\% vs.18\%, Odds ratio: 15 (95\% Confidence interval (CI): 3.3-76), $\mathrm{p}<0.001)$. Furthermore, significantly higher proportion had associated abscess/collections (45.5\% vs. 12\%, OR: 6.3 (95\%CI: $1.8-22), \mathrm{p}=0.001)$. Although a higher proportion of fistulae with specific aetiology were transphincteric fistulae ( $82 \%$ vs. $59 \%$ ), the association was not statistically significant $(\mathrm{p}=0.217)$. The level of the internal opening was comparable between the two groups (Table 1).
Four out of five $(80 \%)$ Crohn's disease patients presented with a complex fistula of which, two were non-recurrent. The remaining patient presented with a simple fistula which was non-recurrent and did not have any associated symptoms to suggest Crohn's disease. Three out of four patients with complex fistulae had altered bowel habits and abdominal pain at the time of presentation. However, the remaining patient with complex fistula had no other symptoms except for perianal discharge. Transphincteric fistulae were seen in 4 patients and one had an intersphincteric fistula. The internal opening was found below the dentate line in 4 patients and above the dentate line in 1 patient.

The two patients who were found to have a non-caseating granuloma had complex transphincteric fistulae with internal openings at the level of the dentate line with associated abscesses. All patients $(n=3)$ with TB had evidence of caseation in the granulomas and were positive for acid-fast bacilli. All presented with recurrent fistulae and of them, two patients had an associated abscess. However, they did not have other systemic symptoms of TB. Two were transphincteric fistulae with an internal opening below and at the level of the dentate line while one patient had a suprasphincteric fistula with the internal opening in the rectum.

The patient who was diagnosed to have a malignancy was a 57-year-old male who presented with a long-standing transphincteric complex fistula with multiple tracts with the internal opening at the level of the dentate line. Furthermore, there was an induration in association with the fistula on rectal examination. Further investigation with imaging and endoscopy revealed that the adenocarcinoma developed in the longstanding fistula tract itself and was not part of a bowel malignancy.

\section{Discussion}

In this retrospective analysis of 215 patients who underwent evaluation for fistula-in-ano, eleven patients (5\%) had histopathological evidence of a specific aetiology. Complex fistula and the presence of an abscess/ collection were found to be associated with a specific aetiology. Other factors such as type of fistula, level of internal opening, recurrence and presence of haemorrhoids were not associated with the diagnosis of a specific aetiology.

Fistula-in-ano is a common cause of perineal sepsis which can be very challenging to treat. Management of fistula-in-ano is complex and includes control of infection, assessment of the anatomy of the fistula tract by examination under anaesthesia and imaging followed by the definitive treatment [13]. Most fistulae-in-ano are idiopathic or cryptoglandular in origin 
Table 1. Associated factors of specific cause in anal fistula

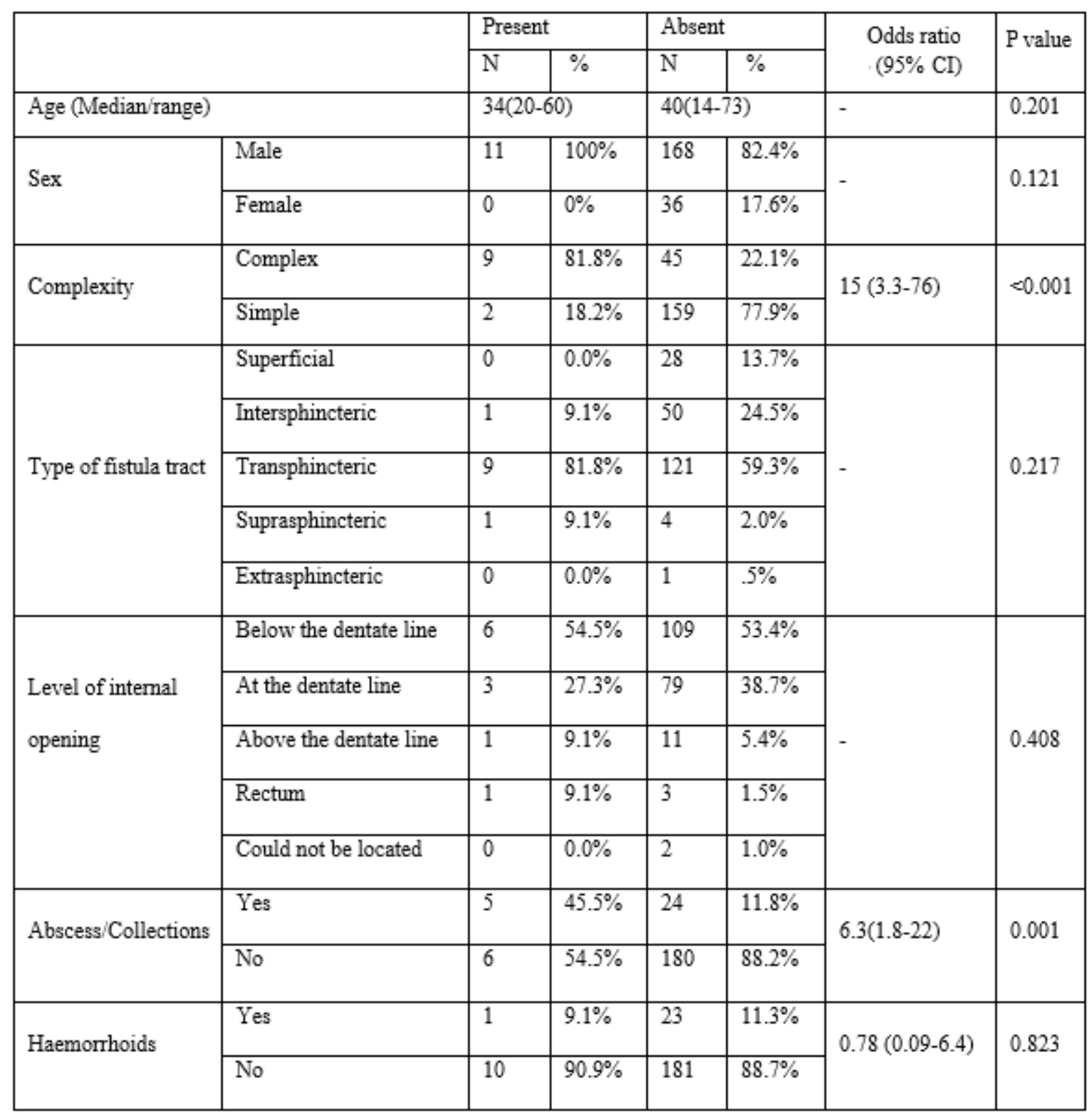

Table 2. Summary of previous studies comparing histological findings of anal fistula

\begin{tabular}{|c|c|c|c|c|c|c|c|c|}
\hline Author & Year & Country & Sample & Study type & TB & Crohn's & Malignancy & Others \\
\hline Sainio & 1983 & Finland & 458 & Population based study & $1(0.2 \%)$ & $6(1.30 \%)$ & None & UC: $7(1.5 \%)$ \\
\hline Shukla & 1988 & India & 122 & Retrospective & $19(15.6 \%)$ & None & None & None \\
\hline Stupart & 2009 & South Africa & 96 & Prospective & $7(7.3 \%)$ & None & None & None \\
\hline Wijekoon & 2010 & Sri Lanka & 84 & Retrospective & $2(2.4 \%)$ & $1(1.2 \%)$ & None & None \\
\hline \multicolumn{2}{|c|}{ Present study } & Sri Lanka & 215 & Retrospective & $3(1.4 \%)$ & $5(2.3 \%)$ & $1(0.5 \%)$ & NCG: $2(0.9 \%)$ \\
\hline
\end{tabular}


which is usually simple, uncomplicated and responds well to treatment. Surgical treatment is the treatment of choice for idiopathic fistulae. However, surgery carries a risk of injury to the anal sphincter complex and can result in complications such as anal incontinence which can be extremely disturbing to the patient $[14,15]$.

However, fistulae occurring secondary to a specific cause is known to occur infrequently, which can be managed pharmacologically. These usually present as complex fistulae-in-ano which are often difficult to manage. Some of the known specific causes are tuberculosis, Crohn's disease, actinomycosis, chlamydia and malignancies [16]. The incidence of TB and acquired immunodeficiency syndrome (AIDS) are on the rise especially in developing countries [17]. Therefore, excluding the possible specific cause is necessary to decide on the definitive treatment. Previous studies that have analysed the histopathological findings have been summarized in table 2 [7-10].

\section{Prevalence of TB in fistula-in-ano}

In a study from Sri Lanka involving 84 patients, TB was confirmed in two $(2.4 \%)$ patients.

Both patients were suspected to have a specific cause clinically as they presented with complex fistulae with poor response to the surgical treatment [10]. In a prospective study of 96 patients from South Africa, 7 (7.3\%) were found to have tuberculosis. Of those, none had systemic manifestations of TB and only one had some evidence of TB in the chest radiograph. [9]. Sainio et al conducted a study in Helsinki and noted that $0.2 \%$ of all fistulae are tuberculous in origin [8].

However, in that population-based study, those with the previous history of TB were not excluded from the analysis. In a study by Shukla et al from India, 122 cases of fistulae inano were analysed and a considerable proportion (15.6\%) were diagnosed as tuberculosis [7]. Anorectal TB is usually associated with pulmonary TB but the occurrence of anorectal TB without pulmonary involvement in also reported in the literature $[18,19]$. In our study 3 patients $(1.4 \%)$ were found to have anorectal TB. Of which 2 were complex fistulae and all three were recurrent fistulae. Furthermore, they did not have any other systemic features of TB and thus histology was useful to clinch the diagnosis.

\section{Prevalence of Crohn's disease in fistula-in-ano}

An anorectal fistula is a known manifestation of Crohn's disease and it usually occurs with other classical symptoms of Crohn's disease. The presentation of perianal Crohn's disease is variable as some (5\%) may even develop anal fistulae before other manifestations of Crohn's disease [19-21]. Although Crohn's disease was previously regarded as a disease of the Western world, it is increasingly being reported in South Asia [22]. In a study by Sainio et al involving 458 patients with anal fistulae, $1.3 \%$ were secondary to Crohn's disease [8]. Interestingly, a higher proportion (1.5\%) were associated with ulcerative colitis. In our study, there were no anal fistulae associated with ulcerative colitis, although an increased incidence of ulcerative colitis is noted in the South Asian region [23].

However, the study conducted by Sainio et al was a population-based study, therefore it is possible that those with previous confirmed ulcerative colitis were also included in the analysis [8]. In a similar study from Sri Lanka including 84 patients, one patient (1.2\%) was diagnosed with Crohn's disease [10]. In the present study, 5 patients $(2.3 \%)$ were found to have Crohn's disease of which, four patients (80\%) presented with complex fistulae. However, the remaining patient presented with a non-recurrent simple fistula without any associated symptoms to suspect the diagnosis of Crohn's disease. This finding is clinically significant as it is evident that non-recurrent simple fistulae can also have a specific aetiology. Interestingly, two out of five patients did not have any other associated symptoms to suggest a possibility of Crohn's disease at the time of presentation. However, they later manifested other symptoms of Crohn's disease. Therefore, histological evaluation in these patients was helpful to diagnose Crohn's disease early.

Malignancy associated with a recurrent anal fistula is a rare entity and it is reported to occur in long-standing fistulae [24]. In our study, one patient was found to have adenocarcinoma with mucinous differentiation. The patient was a 57-year-old male with a history of long-standing fistula for four years. There was an induration in association with the fistula on rectal examination and thus, the history was suggestive. Other studies summarised in table 2 did not find an associated malignant histological finding.

Although a few studies have analysed the histological findings in fistula-in-ano (table 2), the associated factors of fistulae with a specific aetiology were not previously studied. In this study, we have shown that in a few patients, histology was useful in detecting the specific aetiology in the absence of clinical features. This was not reported in previous studies.

Being a retrospective analysis is a limitation. However, we found that in certain cases it was difficult to predict those with a possible underlying disease clinically. Thus, the routine histopathological analysis was useful to detect specific aetiology early. However, the usefulness and costeffectiveness can only be confirmed by large prospective studies. 


\section{Conclusions}

In our study, the prevalence of Crohn's disease, TB and malignancy were $2.3 \%(n=5), 1.4 \%(n=3)$ and $0.5 \%(n=1)$ respectively. Complex fistula and the presence of an abscess/ collection were the only associated factors of a specific aetiology. Other factors such as type of fistula, level of internal opening and presence of haemorrhoids were not associated with a specific aetiology.

Routine histopathological analysis in patients presenting with fistula in-ano may be useful to detect any specific aetiology early which will be helpful in the management of these patients.

\section{Ethics approval and consent to participate}

Ethical approval was obtained from the Ethics Review Committee of the National Hospital of Sri Lanka. Consent is not aplicable as it was a retrospective analysis.

All authors disclose no conflict of interest. The study was conducted in accordance with the ethical standards of the relevant institutional or national ethics committee and the Helsinki Declaration of 1975, as revised in 2000

\section{References}

1. Nelson RL, Abcarian H (2014) Epidemiology, incidence and prevalence of fistula in ano. In: Anal Fistula. Springer, pp 1-3 https://doi.org/10.1007/978-1-4614-9014-2_1

2. Nelson R (2002) Anorectal abscess fistula: what do we know? Surg Clin North Am 82 (6):1139-1151

https://doi.org/10.1016/S0039-6109(02)00063-4

3. Jayarajah U, Wickramasinghe DP, Samarasekera DN (2017) Anal incontinence and quality of life following operative treatment of simple cryptoglandular fistula-in-ano: a prospective study. BMC Res Notes 10 (1):572

https://doi.org/10.1186/s13104-017-2895-Z

4. Jayarajah U, Samarasekera DN (2017) Predictive accuracy of Goodsall's rule for fistula-in-ano. Ceylon Med J 62 (2):97-99. https://doi.org/10.4038/cmj.v62i2.8474

5. Bubbers EJ, Cologne KG (2016) Management of complex anal fistulas. Clin Colon Rectal Surg 29 (1):43 https://doi.org/10.1055/s-0035-1570392

6. Malik A, Nelson R (2008) Surgical management of anal fistulae: a systematic review. Colorectal Dis 10 (5):420-430 https://doi.org/10.1111/j.1463-1318.2008.01483.x

7. Shukla H, Gupta S, Singh G, Singh P (1988) Tubercular fistula in ano. Br J Surg 75 (1):38-39

https://doi.org/10.1002/bjs.1800750114

8. Sainio P Fistula-in-ano in a defined population. Incidence and epidemiological aspects. In: Annales chirurgiae et gynaecologiae, 1983. vol 4. pp 219-224

9. Stupart D, Goldberg P, Levy A, Govender D (2009) Tuberculous anal fistulas-prevalence and clinical features in an endemic area. S Afr J Surg 47 (4):116-121
10.Wijekoon N, Samarasekera D (2010) The value of routine histopathological analysis in patients with fistula in-ano. Colorectal Dis 12 (2):94-96

https://doi.org/10.1111/j.1463-1318.2008.01698.x

11.Whiteford MH, Kilkenny J, 3rd, Hyman N, Buie WD, Cohen J, Orsay C, Dunn G, Perry WB, Ellis CN, Rakinic J, Gregorcyk S, Shellito P, Nelson R, Tjandra JJ, Newstead G, Standards Practice Task F, American Society of C, Rectal S (2005) Practice parameters for the treatment of perianal abscess and fistula-inano (revised). Dis Colon Rectum 48 (7):1337-1342.

https://doi.org/10.1007/s10350-005-0055-3

12.Parks AG, Gordon PH, Hardcastle JD (1976) A classification of fistula-in-ano. The British journal of surgery 63 (1):1-12 https://doi.org/10.1002/bjs.1800630102

13.Shawki S, Wexner SD (2011) Idiopathic fistula-in-ano. World J Gastroenterol 17 (28):3277-3285 https://doi.org/10.3748/wjg.v17.i28.3277

14.Garcia-Aguilar J, Belmonte C, Wong WD, Goldberg SM, Madoff RD (1996) Anal fistula surgery. Dis Colon Rectum 39 (7):723729. https://doi.org/10.1007/BF02054434

15.Ozuner G, Hull TL, Cartmill J, Fazio VW (1996) Long-term analysis of the use of transanal rectal advancement flaps for complicated anorectal/vaginal fistulas. Dis Colon Rectum 39 (1):10-14. https://doi.org/10.1007/BF02048261

16.Seow-Choen F, Nicholls R (1992) Anal fistula. Br J Surg 79 (3):197-205. https://doi.org/10.1002/bjs. 1800790304

17.World Health Organization. Global tuberculosis report 2016 (2016).

18.O'Donohoe M, Waldron R, O'Malley E (1987) Miliary tuberculosis presenting as an acute perianal abscess. Dis Colon Rectum 30 (9):697-698. https://doi.org/10.1007/BF02561691

19. Álvarez J, Gutiérrez V, Del Riego J, García I, Arizcun A, Vaquero C (1992) Úlceras perianales de origen tuberculoso. Aportación de tres nuevos casos. Rev Esp Enferm Dig 81:46-48

20.Lockhart-Mummery H (1975) Crohn's disease: anal lesions. Dis Colon Rectum 18 (3):200-202. https://doi.org/10.1007/BF02587272

21.Hellers G, Bergstrand O, Ewerth S, Holmström B (1980) Occurrence and outcome after primary treatment of anal fistulae in Crohn's disease. Gut 21 (6):525-527 https://doi.org/10.1136/gut.21.6.525

22.Jayarajah U, Navarathne NM, de Zoysa IM, Subramaniam N, Samarasekera N, L Seneviratne S (2017) Crohn's Disease in South Asia. International Journal of Progressive Sciences and Technologies 6(1):12

23.Jayarajah U, Navarathne NMM, Samarasekera N, Subramaniam N, de Zoysa IM, Seneviratne SL (2017) Epidemiology, Pathogenesis and Treatment of Ulcerative Colitis in South Asia. International Journal of Progressive Sciences and Technologies 6 (1):8

24.McAnally AK, Dockerty M (1949) Carcinoma developing in chronic draining cutaneous sinuses and fistulas. Surg Gynecol Obstet 88(1):87-96 